\title{
SISTEM PENUNJANG KEPUTUSAN UNTUK MENETAPKAN KRITERIA KELAYAKAN PENGURUS BADAN EKSEKUTIF MAHASISWA (BEM) DENGAN MENGGUNAKAN METODE ANALITYCAL HIERARCHY PROCESS (AHP), STUDY KASUS PADA STMIK-AMIK RIAU
}

\author{
Hadi Asnal \\ Teknik Informatika, STMIK Amik Riau \\ Jl.Purwodadi Indah KM 10, Panam - Pekanbaru \\ E-Mail : Hadi.asnal@yahoo.co.id
}

\begin{abstract}
ABSTRAK
Badan Eksekutif Mahasiswa yang selanjutnya disingkat (BEM) merupakan salah satu lembaga kemahasiswaan dilingkungan Sekolah Tinggi Manajemen Informatika dan Komputer - Amik Riau( STMIK-AMIK-RIAU), BEM sebagai lembaga kemahasiswaan dengan pengurus terbanyak dilingkungan STMIK-AMIK-RIAU. BEM menjadi roda utama penggerak aktivitas kemahasiswaan. Untuk itu dibutuhkan pengurus dengan kriteria khusus yang dianggap layak untuk menjalankan fungsi utama dari BEM. Selama ini proses untuk menetapkan kriteria kelayakan pengurus tersebut sudah berjalan. Namun proses yang ada hanya berjalan dengan cara mendata calon pengurus lalu melakukan interview. Proses ini jelas tidak efektif dan membuka adanya potensi kecurangan, serta mengesampingkan efisiensi waktu maupun materi. Oleh karena inilah penulis menganggap perlu dibuat rancangan Sistem Penunjang Keputusan untuk menetapkan kriteria kelayakan pengurus BEM. Kriteria yang dimasukkan akan diproses dan dianalisa dengan menggunakan metode Analitycal Hierarchy Process (AHP). SPK ini digunakan untuk menentukan seseorang layak atau tidaknya seseorang menjadi pengurus. Sehingga sistem ini membantu KPUM dalam mengambil keputusan yang tepat tentang pengurus BEM, meliputi tes administrasi dan wawancara. Sistem ini akan melakukan penilaian terhadap 2 komponen yang disebutkan diatas ( Administrasi dan Wawancara) selanjutnya dilakukan perangkingan sebagai bahan rekomendasi jabatan pengurus BEM.
\end{abstract}

Kata Kunci: Sistem, Keputusan, AHP

\begin{abstract}
The Student Executive Board Further abbreviated (BEM) is One Of Student Organizations in environment College of Informatics and Computer Management - Amik Riau (STMIK -AMIK-RIAU), BEM as Student Affairs administrators with most environment ( STMIK -AMIK-RIAU). BEM Become Top wheel activities Student Movers. For a review board of the takes special the criteria considered appropriate to review the functioning Main functions From BEM. During the singer process to review the board sets the eligibility criteria already running. however process just walked with how to record prospective board then conduct interviews. Definitely not process effective and unlock their potential fraud, as well as the exclusion of efficiency in time and material. by because this author considers need created draft decision support system for the review board sets the eligibility criteria for (BEM). The criteria entered will be processed and analyzed using method with analytical hierarchy process (AHP). SPK used to review determine whether or not someone worthy or someone become a caretaker. The system thus helps KPUM hearts singer adopted a decision right on BEM, including the administration of the test and interview. The singer will perform Assessment system against 2 above mentioned component (Administrative and Interview) is then performed on ranking as the material on board Position BEM.
\end{abstract}

Keywords: Systems, Decision, AHP

\section{PENDAHULUAN}

Peran mahasiswa di perguruan tinggi berpengaruh terhadap banyak berbagai aktifitas, mulai dari ranah politik, hukum, sosial, budaya dan lain sebagainya. Aktivitas kemahasiswaan saat ini menjadi salah satu urat nadi dalam kelangsungan hidup mahasiswa di lingkungan kampus. Aktifitas ini tidak terlepas dari perkembangan teknologi. Hal ini membuat 
aktifitas kemahasiswaan harus membuka diri dengan perkembangan teknologi tersebut.

Badan Eksekutif Mahasiswa yang selanjutnya disingkat (BEM) merupakan salah satu lembaga kemahasiswaan dilingkungan STMIK-AMIK Riau, BEM sebagai lembaga kemahasiswaan memiliki pengurus terbanyak. Hal ini jelas menggambarkan BEM merupakan roda utama penggerak aktivitas kemahasiswaan. Untuk itu dibutuhkan pengurus dengan kriteria khusus yang dianggap layak untuk menjalankan fungsi utama dari BEM itu sendiri. Selama ini proses untuk menetapkan kriteria kelayakan pengurus tersebut sudah berjalan. Namun proses yang ada hanya berjalan dengan cara mendata calon pengurus lalu melakukan interview. Proses ini jelas tidak efektif dan membuka adanya potensi kecurangan, serta mengesampingkan efisiensi waktu maupun materi. Atas dasar inilah penulis menganggap perlu membuat " Sistem Penunjang Keputusan Untuk Menetapkan Kriteria Kelayakan Pengurus Badan Eksekutif Mahasiswa (BEM) dengan menggunakan metode Analitycal Hierarchy Process (AHP), Study Kasus pada STMIK Amik Riau ". Sistem penunjang keputusan ini diharapkan akan membawa manfaat khususnya dalam memberikan rekomendasi layak atau tidaknya seseorang menjadi pengurus.

\section{Rumusan Masalah}

Berdasarkan permasalahan yang telah dijelaskan diatas maka dapat dirumuskan suatu permasalahan dalam penelitian sebagai berikut “ Bagaimana merancang Sistem Penunjang Keputusan Untuk Menetapkan Kriteria Kelayakan Pengurus Badan Eksekutif Mahasiswa (BEM) dengan menggunakan metode Analitycal Hierarchy Process (AHP), Study Kasus pada STMIK-AMIK Riau ".

\section{Batasan Masalah}

Agar penelitian dan penulisan ini dapat diselesaikan secara terarah dan tidak adanya penyimpangan dari tujuan penelitian yang ada, maka penulis memiliki batasan-batasan masalah sebagai berikut :

1. Dalam pembuatan sistem penunjang keputusan ini dibuat berdasarkan arahan pembantu ketua 111 bid. Kemahasiswaan STMIK-AMIK Riau ataupun Badan Legislatif Mahasiswa (BLM) selaku pengawas dari Badan Eksekutif Mahasiswa (BEM) berdasarkan mandat yang diberikan pembantu ketua 111 bid. Kemahasiswaan STMIK-AMIK Riau tentang kriteria kelayakan pengurus Badan Eksekutif Mahasiswa (BEM) STMIK-AMIK Riau.

2. Sistem keluaran dari sistem penunjang keputusan ini berupa laporan beragam (tabular, grafik, analisa) yang bersifat penunjang keputusan.

3. Bahasa pemrograman yang digunakan dalam pembuatan sistem ini adalah Hypertext Prepocessor (PHP) sedangkan database akan dikelola menggunakan Database MySQL.

\section{Tujuan}

Penelitian ini bertujuan untuk:

1. Membuat aplikasi sistem penunjang keputusan untuk menetapkan kriteria kelayakan pengurus Badan Eksekutif Mahasiswa (BEM) Study Kasus pada STMIK AMIK RIAU menggunakan 
metode Analytical Hierarchy Process ( AHP ).

2. Sebagai bahan rekomendasi untuk menetapkan kriteria kelayakan pengurus (BEM).

3. Peningkatan terhadap kualitas informasi kelayakan pengurus yang disajikan.

\section{Manfaat}

Adapun manfaat yang akan diperoleh dari penelitian yang penulis laksanakan adalah sebagai berikut :

A. Memberikan informasi dan rekomendasi kepada KPUM tentang kelayakan seorang mahasiswa menjadi pengurus BEM.

B. Memudahkan dalam mencari informasi dan mengetahui tentang siapa saja mahasiswa yang layak menjadi pengurus (BEM).

\section{Sistem}

Menurut Aji Supriyanto (2007:238) sistem adalah sekumpulan elemen yang saling berhubungan, berkumpul bersama-sama untuk melakukan sejumlah prosedur, metode dan cara kerja yang juga saling berinteraksi untuk mencapai suatu tujuan tertentu.

Adapun beberapa karakteristik atau sifat - sifat tertentu yang dimiliki suatu system menurut Aji Supriyanto (2007:238), yaitu :

a. Komponen

Suatu sistem terdiri dari sejumlah komponen yang saling berinteraksi, artinya saling bekerjasama membentuk suatu kesatuan. Komponen - komponen sistem dapat berupa subsistem atau bagian-bagian sistem.

b. Batasan sistem (Boundry)
Merupakan daerah yang membatasi satu sistem dengan sistem lainnya atau dengan lingkungan luar.

c. Lingkungan luar sistem (Environtments )

Lingkungan luar sistem adalah apapun diluar batas sistem yang mempengaruhi operasi sistem. Lingkungan luar sistem dapat menguntungkan yang harus dijaga dan dipelihara serta juga dapat merugikan sistem, dan hal ini harus dikendalikan.

d. Penghubung (Interface)

Merupakan media penghubung antara satu sub sistem dengan sub sistem lainnya.

e. Masukan (Input)

Masukan merupakan energi yang dimasukan kedalam suatu sistem. Masukan dapat berupa masukan perawatan (Maintanance Input) yang merupakan energi yang dimasukan agar sistem dapat beroperasi.

f. Keluaran (Output)

Merupakan hasil dari energi yang diolah dan di klasifikasikan menjadi keluaran yang berguna dan dapat menjadi suatu masukan bagi subsistem yang lainnya.

g. Pengolahan (Process)

Suatu sistem dapat merupakan suatu bagian pengolahan yang akan merubah suatu masukan menjadi suatu keluaran yang biasa disebut informasi.

h. Sasaran (Objectives) dan Tujuan (Goal )

Sasaran dari suatu sistem sangat menentukan masukan yang dibutuhkan oleh suatu sistem dan juga keluaran yang akan dihasilkan oleh sistem tersebut. 


\section{Pengembangan Sistem}

Dari uraian diatas maka penulis menyimpulkan bahwa sistem merupakan sekumpulan komponen yang saling berhubungan satu dengan yang lainnya membentuk satu kesatuan bekerja secara bersama-sama untuk mencapai tujuan tertentu yang telah ditetapkan sebelumnya.

\section{Keputusan}

Menurut Kusrini (2007:7) keputusan merupakan kegiatan memilih suatu strategi atau tindakan dalam pemecahan masalah. Kriteria keputusan adalah :

A. Banyak pilihan/alternative

B. Ada kendala atau syarat

C. Mengikuti suatu pola/model tingkah laku, baik yang terstruktur maupun yang tidak terstruktur.

D. Banyak input/variable

E. Ada faktor resiko

F. Dibutuhkan kecepatan, ketepatan dan keakuratan.

\section{Analytic Hierarchy Process (AHP)}

Menurut Marimin (2004:23) prinsip kerja AHP adalah penyederhanaan suatu persoalan kompleks yang tidak terstruktur, stratejik, dan dinamik menjadi bagian-bagiannya, serta menata dalam suatu hierarki. Kemudian tingkat kepentingan setiap variabel diberi nilai numerik secara subjektif tentang arti penting variabel tersebut secara relatif dibandingkan dengan variabel lain. Dari berbagai pertimbangan tersebut kemudian dilakukan sintesa untuk menetapkan variabel yang memiliki prioritas tinggi dan berperan untuk mempengaruhi hasil pada sistem tersebut .
Pengembangan sistem dapat berarti menyusun atau merancang sistem yang baru untuk menggantikan sistem yang lama secara keseluruhan atau dapat berarti memperbaiki sistem yang sedang berjalan agar dapat mengatasi permasalahan yang ada.

Pendekatan yang digunakan dalam penelitian ini adalah metode Systems Development Life Cycle (SDLC) yang diuraikan seperti pada gambar dibawah ini.

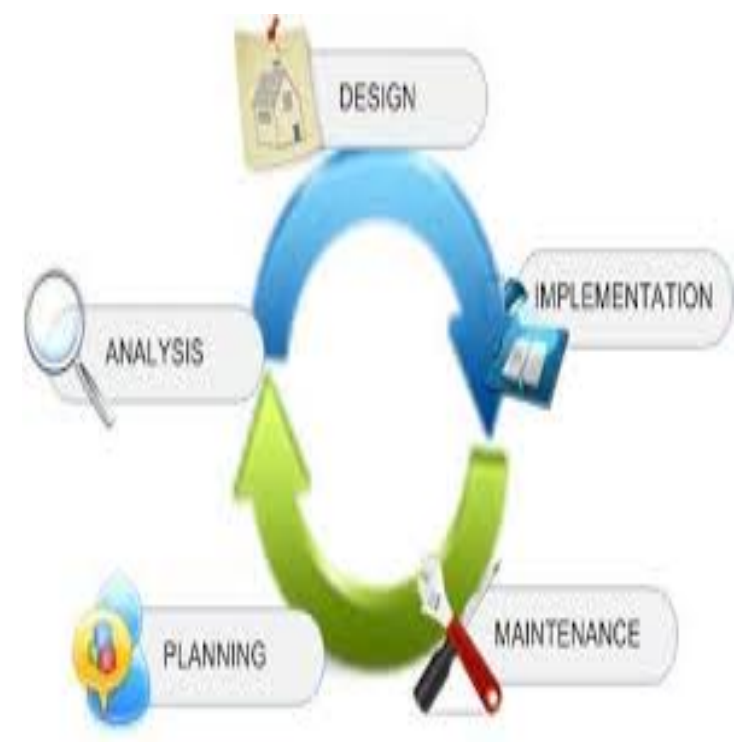

Gambar 2.1 SDLC Model

Sumber : http://www.gunadarma.ac.id

METODE

\section{Analisis Kebutuhan}

Analisis Kebutuhan Fungsional

Kebutuhan fungsional adalah deskripsi tentang aktifitas atau layanan yang harus disedikan oleh system. Fasilitas - fasilitas yang 
harus disediakan oleh sistem penunjang keputusan ini yaitu :

1. menginput data calon pengurus BEM.

2. mengolah dan memberi rekomendasi calon pengurus yang layak/tidak layak.

3. Menyimpan data-data pengurus yang sudah ditetapkan KPUM dan disetujui oleh ketua STMIK-AMIK Riau.

4. Menghasilkan informasi pengurus kepada mahasiswa.

\section{Analisis Kebutuhan Non Fungsional}

Agar dapat berfungsi sebagaimana mestinya, sistem penunjang keputusan ini membutuhkan hal-hal sebagai berikut :

1. $M y S Q L$ sebagai basis data system penunjang keputusan.

2. Web Server. Dalam pengembangan sistem dengan bekerja offline dibutuhkan Apache Web Server.

3. PHP sebagai bahasa pemrograman untuk mengembangkan sistem penunjang keputusan. Pada prakteknya, PHP dibantu dengan HTML dan Cascading Style Sheet (CSS).

4. Web Browser untuk menerjemahkan protocol HTTP dalam grafik. Contoh $\mathrm{Web}$ Browser yang bisa digunakan adalah Mozilla Firefox, Opera, Internet Explorer dan Google Crome.

\section{HASIL}

\section{Perancangan Proses}

Diagram konteks (Context Diagram) merupakan diagram paling tinggi, hanya menggambarkan sistem secara garis besar. Context diagram ini menunjukan hubungan antara sistem dengan lingkungan luarnya.
Diagram konteks di bawah ini akan menggambarkan secara umum aliran dari mana data yang masuk ke sistem dan data apa yang dihasilkan dari sistem dan kemana sistem mengirimkan data atau informasi.

Adapun entitas-entitas yang saling berhubungan dengan Sistem penunjang keputusan untuk menetapkan kriteria kelayakan pengurus Badan Eksekutif Mahasiswa (BEM), studi kasus pada STMIK-AMIK Riau yaitu mahasiswa, KPUM, Puket III dan yang terakhir adalah ketua STMIK-AMIK Riau yang menerima informasi berupa laporan dan melantik pengurus BEM.

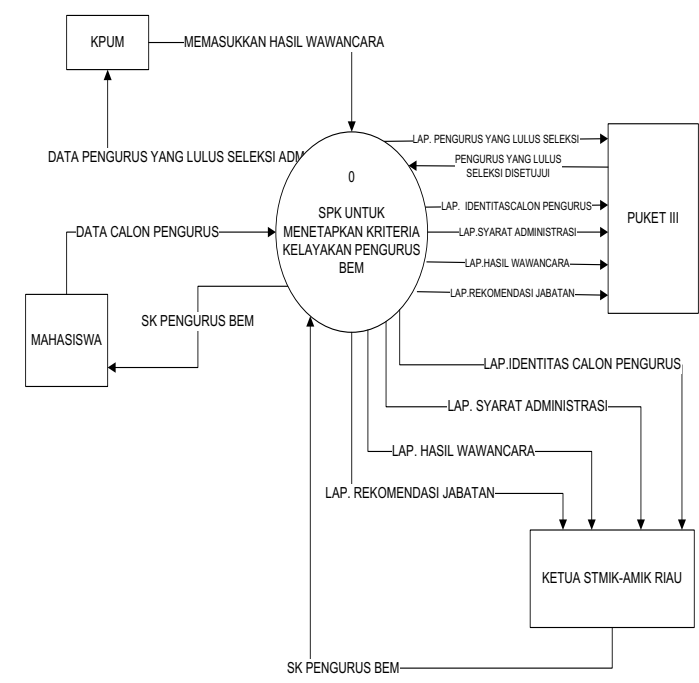

Gambar 1. Konteks Diagram

Data Flow Diagram (DFD) adalah model logika data atau proses yang dibuat untuk menggambarkan dari mana asal data dan kemana tujuan data yang keluar dari sistem, dimana data disimpan, proses apa yang dihasilkan data tersebut dan interksi antara data yang tersimpan dan proses yang akan dikenakan pada data tersebut. 


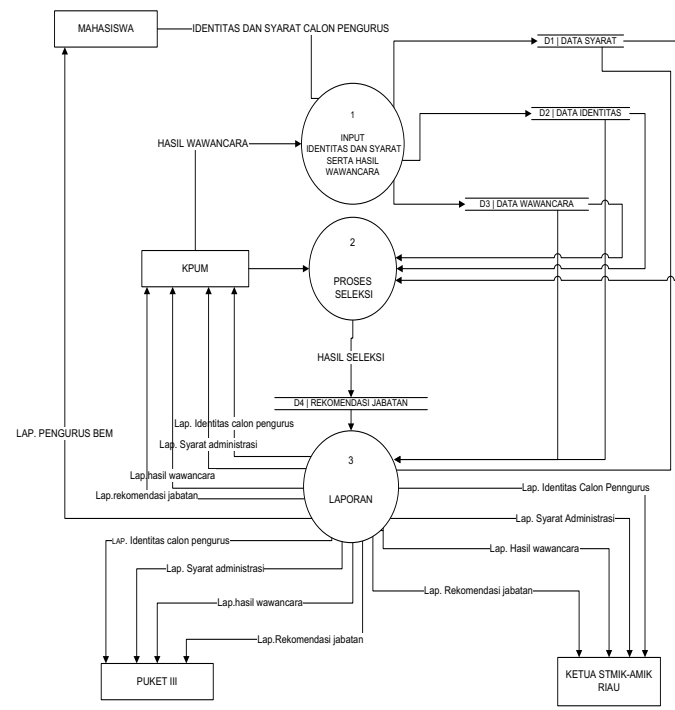

Gambar 2. Data Flow Diagram

\section{Analytic Hierarchy Proces (AHP)}

Model analytical hierarchy process mempunyai kemampuan dalam memecah masalah multikriteria. Model pendukung keputusan ini akan menguraikan masalah multikriteria tersebut menjadi suatu hirarki.

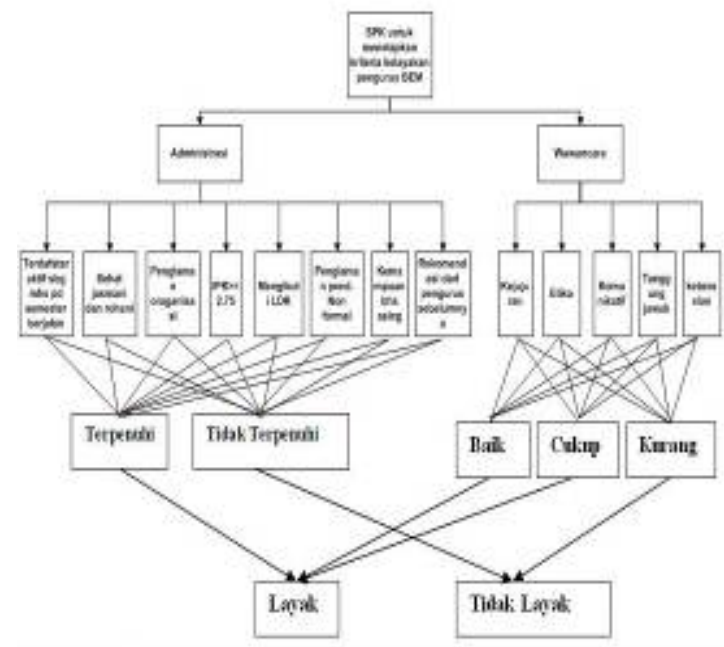

Gambar 3. Struktur Hirarki
Tahap implementasi sistem merupakan tahap uji coba agar sistem siap untuk di operasikan. Tahap implementasi sistem penunjang keputuusan untuk menetapkan kriteria kelayakan pengurus BEM ini bisa menggunakan Sistem Operasi Windows, Linux dan lainnya. Adapun spesifikasi dari perangkat keras dan perangkat lunak yang digunakan dalam tahap implementasi sistem ini adalah :

A. Perangkat keras (Hardware)

1. Laptop dengan model CompaqCQ42 dan jenis processor Intel DualCore.

2. Random Access Memory (RAM) berkapasitas $4 G B D D R 3$ sebagai tempat penyimpanan data sementara.

3. Harddisk berkapasitas 640 Gigabyte.

4. VGA Nvidia Geforce GT 540M 2 Gb.

5. Modem Huawei Vodafone 7.2 Mbps.

B. Perangkat Lunak (Software)

a. Sistem operasi Microsoft Windows 7

b. Bahasa pemrograman PHP dan Database $M y S Q L$

c. Xampp versi 1.7.0

d. Google Chroome Versi 24.0.1312.57

\subsection{Halaman Home}

Halaman Home merupakan halaman yang pertama kali tampil ketika memasukkan alamat website.

\section{Implementasi}




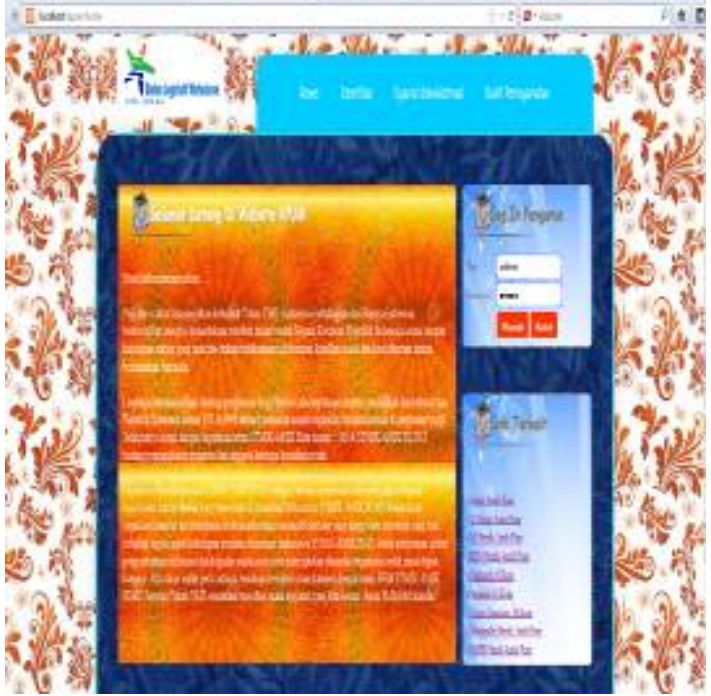

Gambar 4. Tampilan Halaman Home

Tampilan Halaman Identitas. Tampilan halaman untuk menginputkan identitas calon.

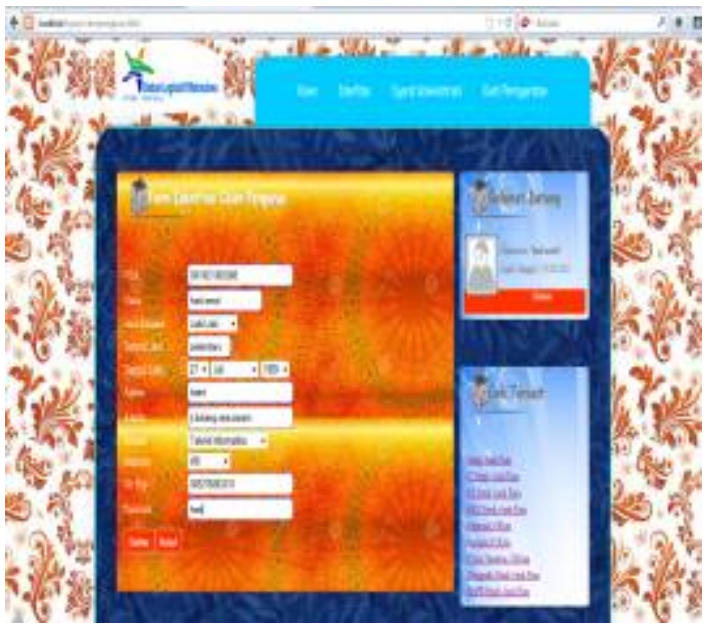

Gambar 5. Tampilan Halaman Identitas

Tampilan Halaman Input Syarat Administrasi. Halaman syarat administrasi ini digunakan untuk inputkan syarat-syarat administrasi oleh calon.

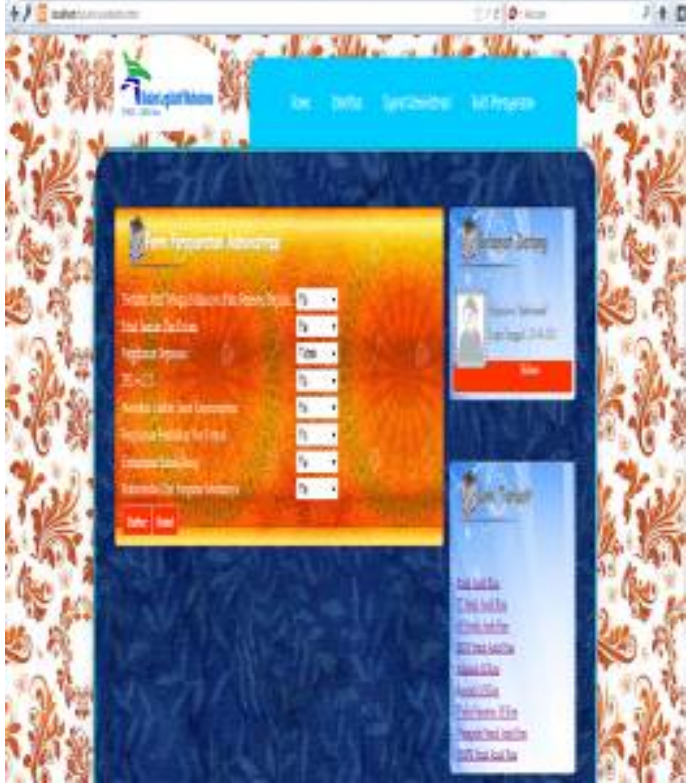

Gambar 6. Tampilan Halaman Input Syarat ADM

Tampilan Halaman Bukti Persyaratan. Tampilan form ini untuk menginput bukti syarat-syarat administrasi.

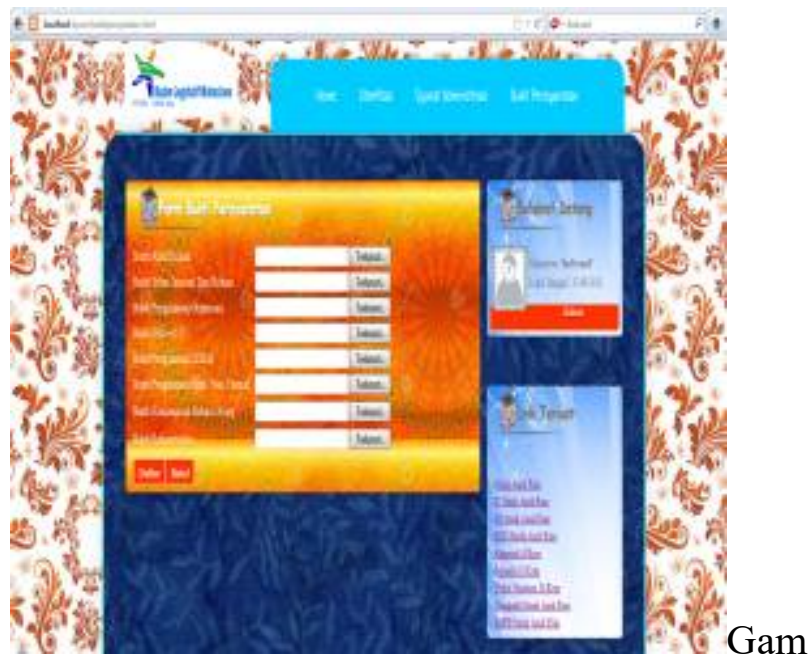

bar 7. Tampilan Halaman Bukti Persyaratan

Tampilan Login Admin. Untuk masuk kehalaman admin harus login terlebih dahulu. 


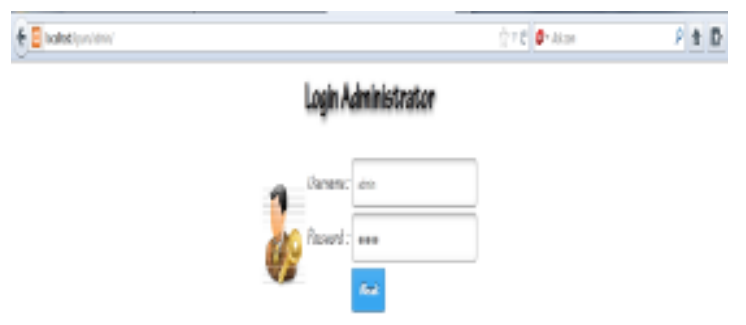

Gambar 8. Tampilan Login Admin

Tampilan Halaman Utama Admin. Tampilan ini merupakan yang pertama muncul setelah melakukan login, klik calon pengurus untuk melihat daftar seluruh calon pengurus, klik syarat administrasi untuk melihat daftar seluruh Syarat administrasi calon, klik hasil wawancara untuk melihat daftar seluruh hasil wawancara, klik rekomendasi jabatan untuk melihat daftar seluruh rekomendasi calon pengurus .

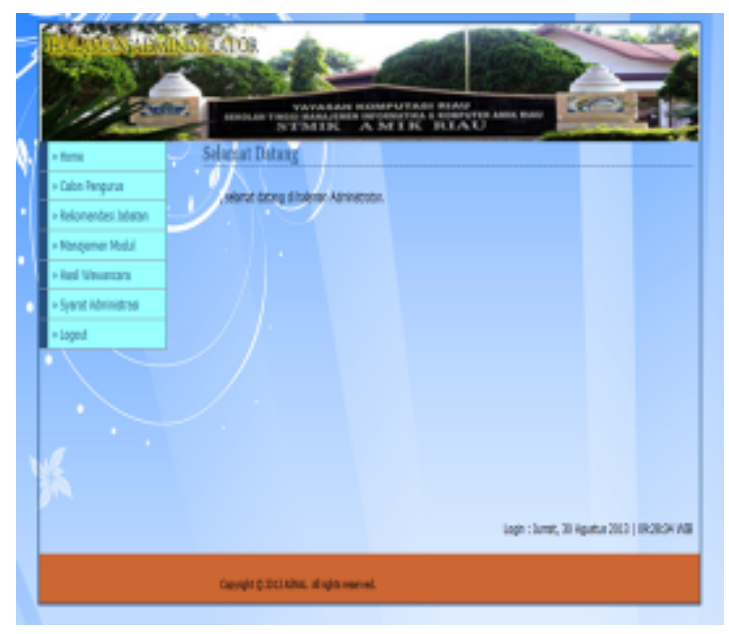

Gambar 9. Tampilan Halaman Utama Admin

Tampilan Daftar Calon Pengurus. Halaman ini merupakan daftar semua calon pengurus, untuk mencetak laporan identitas calon silahkan klik tombol laporan identitas calon pengurus.

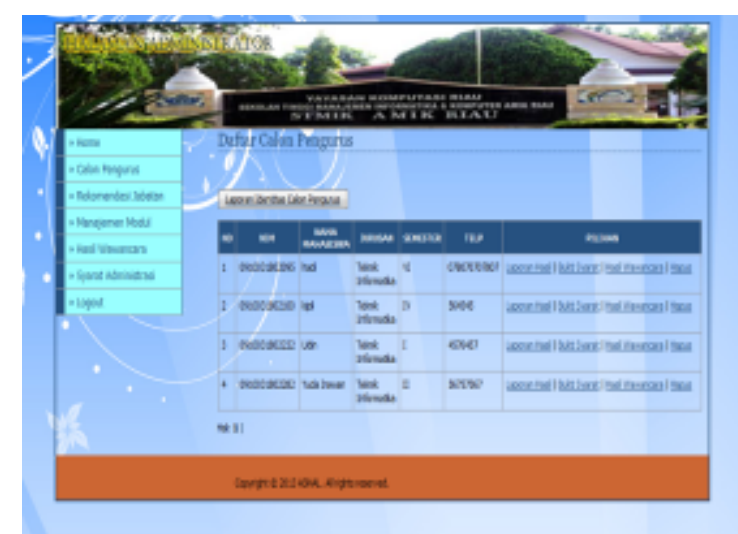

Gambar 10. Tampilan Daftar Calon Pengurus

Tampilan Form Input Hasil Wawancara. Halaman ini merupakan form untuk menambahkan hasil wawancara yang dilakukan KPUM kepada calon pengurus yang telah memenuhi syarat administrasi.

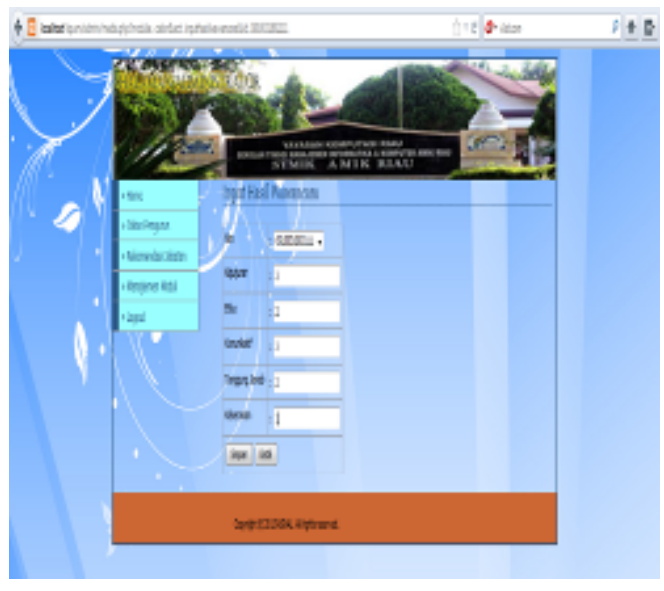

Gambar 11 Tampilan Form Input Hasil Wawancara

Tampilan Form Hasil Keseluruhan. Form untuk melihat secara keseluruhan hasil yang diperoleh calon. 

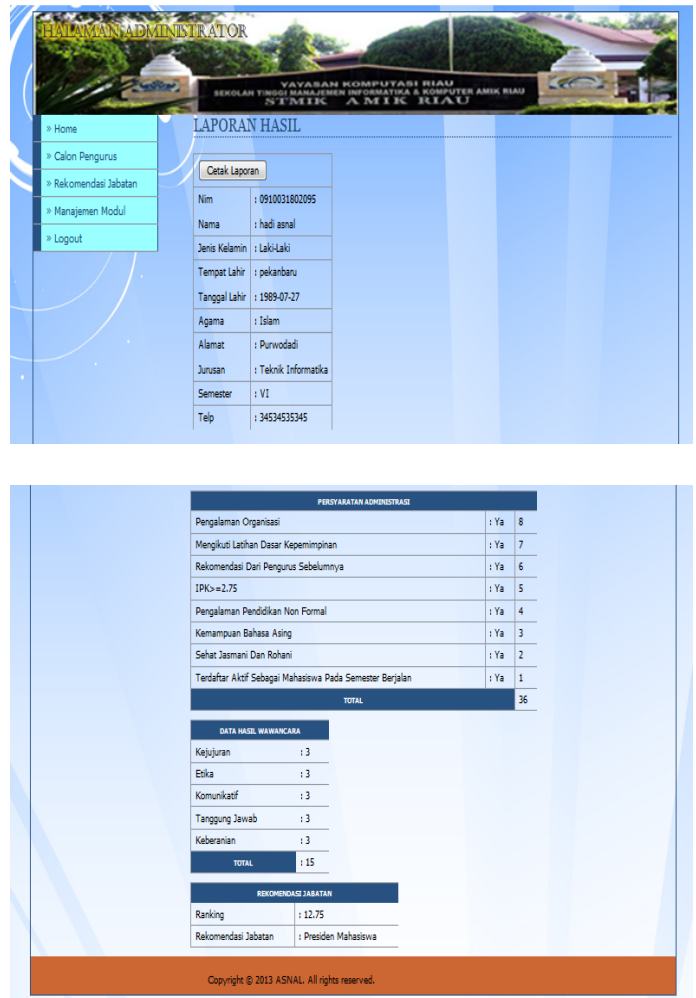

Gambar 12. Tampilan Form Laporan Hasil

\section{KESIMPULAN}

Berdasarkan hasil analisa dan pembahasan serta uraian dari bab-bab sebelumnya maka dapat disimpulkan :

1. Sistem baru ini dapat membantu pihak BLM/KPUM selaku penyelenggara dalam menetapkan kriteria kelayakan pengurus Badan Eksekutif Mahasiswa (BEM) STMIK-AMIK-RIAU.

2. Sistem ini dapat membantu pihak BLM/KPUM untuk menyelesaikan kesulitan dalam menangani masalah pengumpulan data calon pengurus.

3. Dengan menerapkan sistem ini maka proses penyeleksian akan berjalan dengan baik sehingga proses yang lain tidak akan mengalami pengunduran waktu .

4. Proses yang baru ini berbasis pada perangkat komputer sehingga buktibukti penyeleksian tersimpan dengan baik dan suatu waktu dapat digunakan untuk menjadi bukti bilamana ada dugaan kecurangan.

\section{DAFTAR PUSTAKA}

[1]. Kusrini. 2007. Konsep dan Aplikasi Sistem penunjang Keputusan. Yogyakarta : CV. ANDI OFFSET

[2]. Efraim, Jay E Aroson, Ting peng liang. 2007. Decision Support System. Yogyakarta: ANDI Yogyakarta

[3]. Turban, E.,dkk. 2005. Decision Support System and Intelligent System. Yogyakarta: Andi

[4]. C J Date. 2005. Pengenalan Sistem Basis Data jilid 2. Jakarta : Perpustakaan Nasional

[5]. Privida Kristiono. 2008. Pemograman Databse Tingkat Lanjut dengan VB 6.0 Jakarta : Elex media Komputindo

[6]. Aji Supriyanto. 2007. Sistem Informasi. Jakarta : Elex Media Komputindo

[7]. Jogiyanto.2005.Analisan\&Desain. Yogyakarta:Andi

[8]. Al-Bahra bin Ladjamuddin, (2005), Analisis dan Desain Sistem Informasi, - Yogyakarta:Graha Ilmu.

[9]. Kadir, Abdul, (2008 ), Dasar Pemograman Web Dinamis Menggunakan PHP, Edisi 3, Yogyakarta : Andi. 